\title{
ANÁLISE MULTITEMPORAL DA BACIA AMBIENTAL DO IMBIRUSSU EM CAMPO GRANDE - MS
}

\section{Rennan Vilhena Pirajá ${ }^{1}$ \\ Mauro Henrique Soares da Silva ${ }^{2}$}

RESUMO: Este trabalho tem por objetivo realizar uma análise multitemporal do uso e ocupação do solo na Região Urbana do Imbirussu em Campo Grande - MS. Foram utilizadas imagens do satélite Landsat 5 (TM) dos anos de 1985, 1998 e 2010, as quais foram geoprocessadas para gerar os mapas de uso e ocupação do solo, assim como as quantificações das áreas classificadas. Os resultados apontam o aumento da área correspondente aos espaços urbanos em quase o dobro durante o período analisado, estando relacionado ao crescimento populacional e ao intenso fluxo migratório ocorrido após a década de 1970. Os espaços industriais também obtiveram crescimento considerável, influenciados pelo processo de desconcentração industrial. Em relação aos espaços rurais houve uma diminuição gradativa, mas não acentuada destes espaços. Para os vazios urbanos houve uma redução significativa, caracterizando a princípio uma urbanização desordenada da região durante as décadas de 1985 e 1998. Para os espaços naturais, referente à mata de galeria do córrego Imbirussu, já modificada por interferência antrópica de forma positiva, relacionada à criação do Parque Linear Imbirussu e de forma negativa pela descarga de efluentes industriais no córrego. Os resultados apresentados demonstram relações existentes entre sociedade e ambiente assim como as mudanças ocorridas na paisagem pela dinâmica do espaço e retratam a

\footnotetext{
${ }^{1}$ Mestrando em Meio Ambiente e Desenvolvimento Regional. Univ. Anhanguera/UNIDERP rennanvp@hotmail.com

${ }^{2}$ Doutor em geografia. Univ. ANHANGUERA/UNIDERP. Professor do Programa de Mestrado e Doutorado em Meio Ambiente. mauro.soares@uniderp.edu.br
} 
relevância da realização de estudos temporais sobre o uso e ocupação do solo em bacias hidrográficas como forma de interpretar e conduzir o desenvolvimento regional sustentável, contribuindo como um modelo de análise das transformações exercidas pelo homem sobre o meio.

PALAVRAS-CHAVE: Uso e Ocupação do Solo. Sensoriamento Remoto. Espaço. Paisagem.

\section{INTRODUÇÃO}

Segundo Santos (2004) o processo de ocupação do espaço, assim como os planejamentos, são reflexos de um complexo quadro de acontecimentos históricos e de situações político-social-econômicas, assim como, ambiental e cultural, peculiar a cada país ou região. O Brasil, como outros países, sempre idealizou seus planejamentos em função dessa história e de suas próprias situações e está dando os primeiros passos no processo de construção teórico sobre planejamento ambiental, e em contínuo processo de revisão, nestas últimas décadas.

Conforme Florenzano (2011), no Brasil, o processo acelerado da urbanização tem provocado impactos negativos ao meio ambiente e a qualidade de vida da população. As técnicas de sensoriamento remoto contribuem efetivamente com a análise e elaboração de um diagnóstico que subsidie o planejamento do uso do solo das áreas urbanas. A expansão da mancha urbana de uma cidade, ou seja, o crescimento da área ocupada por essa cidade, bem como a direção (norte, sul, leste e oeste), podem ser facilmente detectados por meio de imagens de satélites. "Os sistemas e técnicas de sensoriamento remoto, estabelecidos a partir do início dos anos 1970, podem permitir o estudo da evolução ambiental de determinadas regiões do globo, exibindo, principalmente, as modificações ocorridas na cobertura do solo" (Paranhos Filho et al., 2008, p.164,).

Ao se comparar as características de um mesmo local em diferentes épocas e se observar as modificações ocorridas, tem-se a análise multitemporal. Estudos 
multitemporais já foram conduzidos com resultados satisfatórios em várias regiões do mundo interessadas em evidenciar mudanças ambientais (Paranhos Filho et al., 2008).

A área de estudo corresponde à bacia ambiental ${ }^{3}$ do Imbirussu (Figura 1), caracterizada por estar dentro do perímetro urbano de Campo Grande - MS e abranger diferentes formas de ocupação do espaço, onde se contrastam paisagens, rurais, urbanas e industrial, ambas mescladas a fragmentos e/ou elementos constituintes de paisagens naturais.

O perímetro da bacia ambiental adotado corresponde ao zoneamento estabelecido pela PLANURB para fins de planejamento urbano de Campo Grande instituído como base cartográfica pelo plano diretor de 1995 que teve como critério as micro bacias urbanas da cidade.

Diante deste contexto, o planejamento torna-se de extrema importância para a locação de infraestruturas que atendam a dinâmica de crescimento da região proporcionando o desenvolvimento sem a perda da qualidade ambiental que está diretamente relacionada com a qualidade de vida.

Este trabalho justifica-se por colaborar para o debate sobre o efeito da pressão das atividades econômicas e do processo de ocupação do espaço como modeladores da paisagem.

A pesquisa tem por objetivo principal investigar as mudanças ocorridas na paisagem da Região Urbana do Imbirussu em Campo Grande, Mato Grosso do Sul, através de um estudo temporal do uso e ocupação do solo, utilizando imagens de satélite dos anos 1985, 1998 e 2010.

\footnotetext{
${ }^{3}$ Bacia ambiental é uma proposta de área de estudo voltada ao ambiente urbano. Caracteriza-se pelo somatório de unidades territoriais definidas pelas drenagens naturais de águas superficiais, drenagens antrópicas (águas estocadas, servidas e em uso) e áreas de ações socioeconômicas, inclusive considerando-se aquelas que abrangem os espaços de interesse dos principais grupos sociais. É um espaço de conformação dinâmica que valoriza as modificações feitas pelo homem no desenho natural da paisagem e as relações ambientais de sustentabilidade de ordens ecológica, econômica e social (SANTOS, 2004).
} 


\section{stoment Fórum Ambiental}

da Alta Paulista

ISSN 1980-0827

Volume 9, Número 2, 2013

Bacias Hidrográficas, Planejamento e

Gestão dos Recursos Hídricos

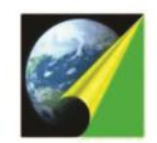

ANAP

A partir da criação de mapas temáticos pretendeu-se demonstrar a dinâmica do espaço e a evolução do uso e ocupação do solo. Assim, com os resultados obtidos, puderam-se discutir as relações existentes entre desenvolvimento e meio ambiente.

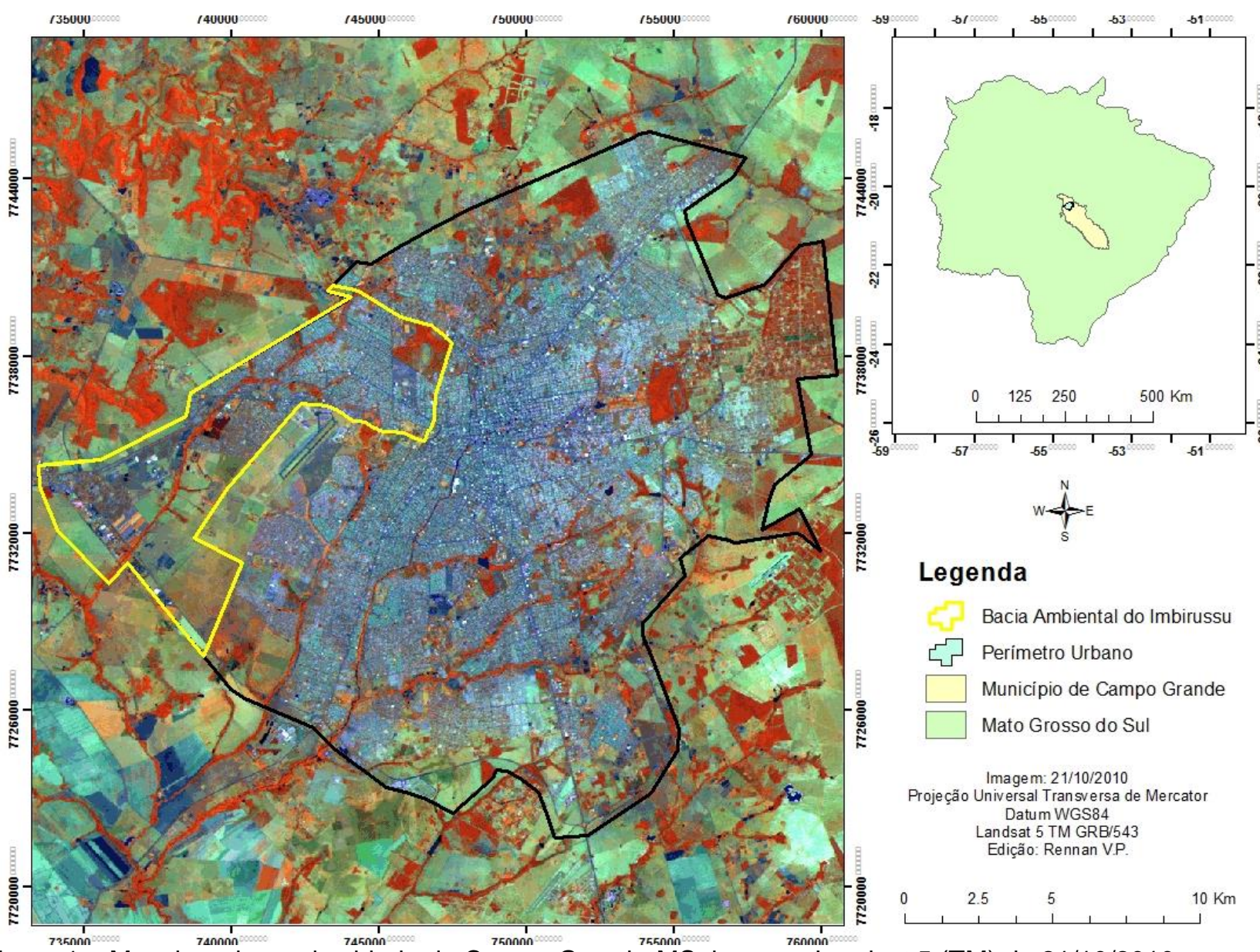

Figura 1 - Mancha urbana da cidade de Campo Grande-MS, imagem Landsat 5 (TM) de 21/10/2010.

\section{MATERIAIS E MÉTODOS}

O trabalho foi desenvolvido com o software SPRING, versão 5.1 .8 fornecido pelo INPE, no qual foram utilizadas as imagens do satélite Landsat 5 (TM) ambos os materiais fornecidos gratuitamente pelo sitio do INPE, sendo que as imagens são recortes das cenas 225-74(órbita-ponto), com resolução espacial de 30m.

Foram aplicadas técnicas de interpretação para as imagens datadas em 17/11/85, 21/11/98, 21/10/10, sendo essas datas o principal critério de escolha das imagens, uma 
vez que, os meses se referem a mesma estação do ano, no qual o aspecto da paisagem natural possui um mesmo padrão, e coincidem com o período em que foi realizado 0 trabalho de campo para registro fotográfico da paisagem "in loco" no ano de 2012, no qual foram utilizadas como chaves de interpretação das imagens Landsat e áreas de treinamento para as classes estabelecidas (Quadro 1).

O critério de escolha dos anos das imagens está relacionado com as mudanças ocorridas após 1970, devido ao intenso fluxo migratório da zona rural para as cidades, as consequências desse acelerado processo de migração e a falta de planejamento do poder público em absorver esse contingente, assim como, a necessidade de racionalizar esses espaços através da inserção de um novo paradigma de desenvolvimento que ganha notoriedade em 1987 no relatório "Nosso Futuro Comum" chamado "Desenvolvimento Sustentável".

QUADRO 1 - Classes de uso e ocupação do solo na Região Urbana do Imbirussu.

\begin{tabular}{|c|l|}
\hline \multicolumn{1}{|c|}{ Classes } & \multicolumn{1}{|c|}{ Descrição } \\
\hline Espaços Urbanos & $\begin{array}{l}\text { Foram considerados ruas, avenidas, logradouros, praças, } \\
\text { estacionamentos, cemitério, estabelecimentos comerciais e residências. }\end{array}$ \\
\hline Espaços Rurais & Está relacionada a áreas de pastagem e agricultura. \\
\hline Espaços industriais & $\begin{array}{l}\text { Abrange toda sua estrutura física incluindo pátios de estacionamentos, } \\
\text { lagoas artificiais e áreas verdes pertencentes às indústrias. }\end{array}$ \\
\hline Espaços Naturais & $\begin{array}{l}\text { Foi considera a Mata de Galeria do córrego Imbirussu. } \\
\text { Vazios Urbanos }\end{array}$ \\
$\begin{array}{l}\text { É referente a glebas e terrenos baldios que não se confundem com o } \\
\text { ambiente construído }\end{array}$ \\
\hline
\end{tabular}

Fonte: Adaptado de IBGE(2006)

Para a realização das correções geométricas utilizou-se a ferramenta registro de imagens do SPRING, no qual foi utilizada como referência a cena de 22/09/2011 e 225 074 (órbita-ponto) ${ }^{4}$ georeferenciada no Sistema de Coordenadas Universal Transversa de

\footnotetext{
${ }^{4}$ Em: <www.glcfapp.glcf.umd.edu:8080/esdi/>. Acesso em 03 novembro 2012.
} 
Mercator (UTM) e Datum WGS84, para as quais foram estabelecidos 10 pontos de controle (CARVALHO e LAENDER, 2007).

Após as etapas de pré-processamento das imagens, tais como recorte da região em estudo, composição de bandas e aplicação de contraste, no software SPRING, foi executada exportação da imagem de 2010 em formato tif para o software ARCGIS versão 10, fornecido pelo Laboratório de Geografia da UFMS, para confecção de mapas com as chaves de interpretação.

Foi realizada a composição colorida, também conhecida por falsa cor, associando as bandas 453 às cores primárias: vermelho $(R)$, verde $(G)$ e azul $(B)$, pois tal combinação tornou mais eficiente à interpretação, principalmente quanto ao tipo de vegetação, por captarem a faixa do espectro eletromagnético referente ao vermelho, infravermelho próximo e infravermelho médio (IBGE, 2006).

A etapa de elaboração dos mapas de uso e ocupação do solo e quantificação das áreas classificadas foi totalmente realizada no SPRING com auxílio do módulo de confecção cartográfica SCARTA e partiu das seguintes etapas: segmentação, na qual a imagem foi dividida em regiões espectralmente homogêneas através do método Crescimento de regiões; classificação supervisionada, no qual foram selecionadas em classes (Quadro 1) as amostras de treinamento que possuem similaridades em suas respostas espectrais (representada por pixel ou grupo de pixels) utilizando o algorítimo Battacharya e a quantificação das áreas classificadas através da ferramenta Medidas de Classes, possibilitando a comparação e contextualizar a evolução das classes para as datas escolhidas (IBGE, 2006).

\section{RESULTADOS E DISCUSSÃO}

A partir da metodologia selecionada foi possível realizar cartas temáticas representando a evolução do processo de uso e ocupação do. Analisando as cartas de uso e ocupação do solo (Figura 2), assim como, a quantificação das áreas estabelecidas na classificação (Figura 3), observa-se grandes mudanças na paisagem da região realizadas pelo processo de ocupação do espaço ao longo das três últimas décadas.

Partindo-se do percentual de área dos espaços urbanos de 1985, houve um aumento significativo, passando de $25 \%$ para $34 \%$ em 1998 e $47 \%$ em 2010. Este 
aumento justifica-se pelo crescimento populacional que chegou a ser multiplicado em até 5,6 vezes entre 1970 e 2010 em Campo Grande (PLANURB, 2012)

Analisando a taxa de crescimento populacional de Campo Grande, no período de 1970 a 1980 observou-se a maior taxa média geométrica anual, 7,61\% desde então a taxa de crescimento demográfico vem desacelerando, em função da acentuada redução dos níveis de fecundidade e redução do fluxo migratório (PLANURB, 2012).

Porém o incremento médio anual tornou-se auto, devido a grande quantidade de pessoas no ambiente urbano, fato observado na evolução demográfica da Região Urbana do Imbirussu que em 1991 apresentou 71.015 habitantes, em 2000, 89.865 e em 2010 foram contabilizadas 98.752 habitantes (PLANURB, 2012) apresentando um incremento médio aproximado de 13.000 pessoas a cada 10 anos que consequentemente avança sobre as classes espaços rural e vazios urbanos, assim como, para os bairros mais periféricos (Nova Campo Grande e Núcleo Industrial), no qual se tem um menor adensamento populacional, porém com a maior taxa média geométrica de crescimento populacional da região. 

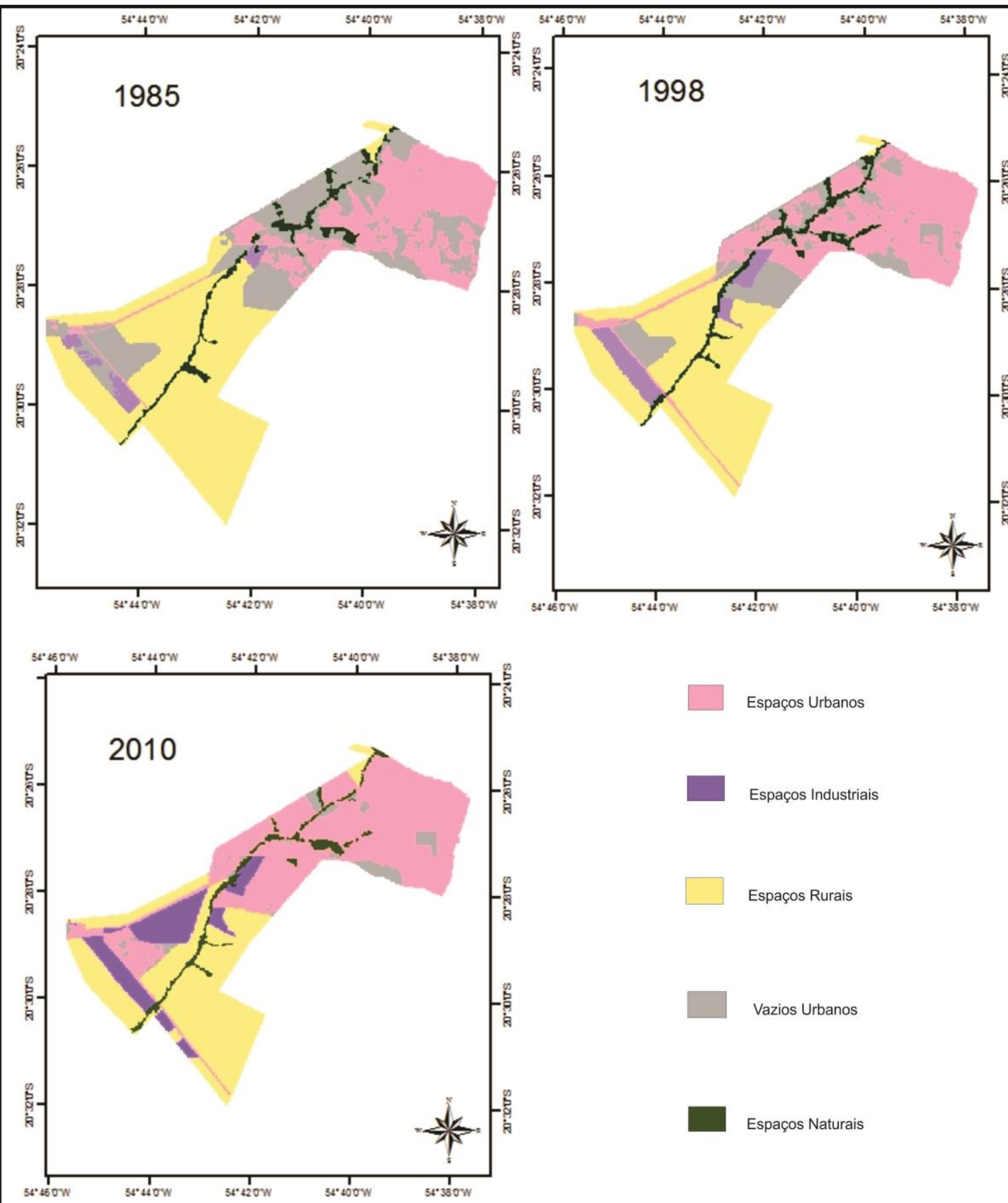

Espaços Urbanos

Espaços Industriais

Espaços Rurais

Vazios Urbanos

Espaços Naturais

Projeção Universal Transversa de mercator Datum WGS84 Zona 21

Digitalização e edição: Rennan V.P. 2013

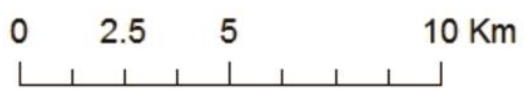


Figura 2: Evolução temporal do uso e ocupação do solo na região urbana do Imbirussu.

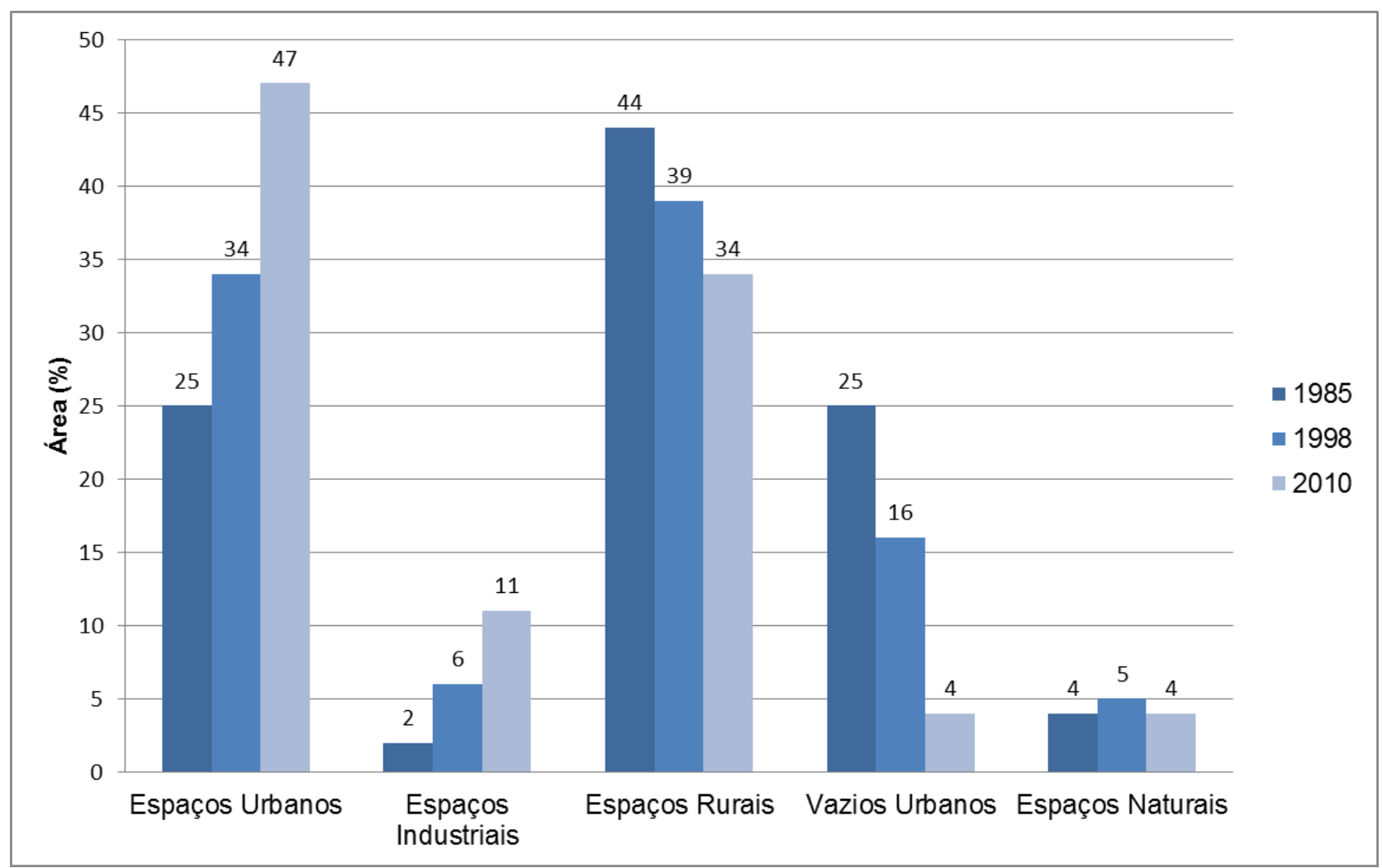

Figura. Quantificação da evolução do uso e ocupação da bacia ambiental do lbirussu por classes mapeadas.

A classe espaços industriais encontrava-se com $2 \%$ em 1985, aumentando para $6 \%$ em 1998, quantificação referente ao crescimento do núcleo industrial Indubrasil, instalado em 1977 pela Prefeitura Municipal com 200 hectares, e aumentando significativamente para $11 \%$ em 2010, no qual pode-se afirmar que este aumento está ligado ao Programa de Incentivos para o Desenvolvimento Econômico e Social de Campo Grande (PRODES), implantado em 1999, pela Lei Complementa n. 29 (PLANURB; 2012).

Um dos resultados do PRODES foi a criação do Polo Empresarial Conselheiro Nelson Benedito Netto (Polo Empresarial Oeste) em 2001, localizado na Região Urbana do Imbirussu, em uma área de 243 hectares, próximo ao núcleo industrial Indubrasil (PLANURB, 2012). Portanto observa-se o conceito de desconcentração industrial como reversão da polarização associada às deseconomias de aglomeração das regiões 
metropolitanas e que segundo Marcondes (1999) é incentivada através de medidas de politicas públicas reorientadas, com estímulos a atividade industrial em determinadas regiões.

Em relação aos espaços rurais que em 1985 encontrava-se com 44\% da área total da região, em 1998 com 39\% e em 2010 com 34\%, observou-se uma diminuição gradativa destes espaços. A classe abrange tanto a agricultura quanto a pecuária, sendo esta última a mais expressiva, verificada nas visitas de campo, assim como analisadas nas imagens de satélite.

Seguindo os parâmetros de interpretação de imagens Landsat 5 (EMBRAPA, 2000) observa-se também em relação aos espaços rurais que as mudanças na paisagem estão relacionadas as formas de emprego da técnica no manejo do pasto.

$\mathrm{Na}$ imagem de 1985 observa-se parcelas de uma vegetação mais viva, indicando a presença de uma maior biomassa, característica de uma pastagem natural, ora alternando-se com grandes porções de um solo escuro acinzentado de forma irregular, indicando característica de queimadas em área de pastagem extensiva, prática bastante utilizada no cerrado para a renovação do pasto.

$\mathrm{Na}$ imagem de 1998 observa-se áreas rurais com características de um solo parcelado, devido às diferenças espectrais em forma de polígonos, alternando-se em solos expostos de coloração escura que caracterizam um solo adubado e áreas de pastagem em diferentes estágios, caracterizando uma cultura de rotatividade.

Tanto na imagem de 2010 quanto na pesquisa de campo os vários tipos de pasto, principalmente com a utilização da braquiária, no qual foram constadas, em campo, diferentes espécies, principalmente a margem esquerda da BR-262, sentido oeste, com o sistema de pastejo rotativo de gado, utilizado como campo experimental da EMBRAPA gado de corte.

Para a classe vazios urbanos, que em 1985 encontrava-se com 25\%, em 1998 com $16 \%$ e em 2010 com 4\%, foi verificada uma redução significativa, a qual permite a confirmação que a pressão do aumento dos espaços urbanos foi praticamente sobre estes espaços dantes vazios. 
Segundo a PLANURB (2012), a expansão da malha urbana da cidade se deu de forma descontinua com o surgimento de áreas urbanizadas entremeada de glebas não loteadas e desligadas da trama urbana. A partir de 1960 grandes porções do terreno começam a ser loteados para abrigar a população menos favorecida que imigrava para Campo Grande, tendo intensificado na década de 1970 fazendo com que parte do adensamento da cidade se concentrasse nas saídas da cidade, acompanhando o sistema viário.

Segundo Freitas (2005) a especulação imobiliária acaba por ser uma das causas do processo de ocupação desordenado do espaço. Pois as áreas ociosas dentro do perímetro urbano diminuem a oferta de terra útil, gerando o aumento do preço da terra e empurrando os mais pobres para áreas periféricas fomentando o processo de segregação social e espacial ao tornar a cidade cada vez mais espraiada.

$\mathrm{Na}$ classe espaços naturais, referente à resposta espectral da mata de galeria do córrego Imbirussu, em 1985 encontrava-se com 4\%, em 1998 com 5\% e em 2010 com $4 \%$, observa-se praticamente a não evolução dessas áreas, sendo possível afirmar que o pequeno aumento em 1998 deve-se ao crescimento de vegetação secundária em áreas de vazios urbanos junto a mata de galeria do córrego, gerando uma pequena anexação entre a vegetação arbórea e a mata secundária durante a segmentação.

Além disso, a redução dessa classe em 2010 é referente à ocupação destes espaços vazios e a definição do traçado das ruas e avenidas associadas a construção do Parque Linear Imbirussu entre 2006 e 2011, no qual observa-se a intervenção antrópica em sistema hidrográfico de ambiente urbano de forma positiva, através de uma nova relação de uso dos espaços naturais, contemplando a relação harmônica entre desenvolvimento e meio ambiente, atendendo aos princípios da sustentabilidade.

Entrando em contradição como o trecho do córrego próximo ao Núcleo Industrial e o Polo Empresarial Oeste, ainda isentos de assistência, as únicas intervenções antrópicas ocorridas dizem respeito ao uso deteriorante, isso se dá devido ao fomento da ocupação industrial sem a real preocupação com o meio ambiente, conforme constatado em alguns pontos que servem como escoadouro de efluentes industriais tanto do Polo Empresarial 
Oeste quanto do Núcleo Industrial, sendo, portanto zonas industriais ainda precárias em infraestrutura básica, as quais segundo PLANURB (2012) cobertas apenas por infraestrutura básica de revestimento primário em todas as vias, drenagem pluvial e áreas para serviços públicos.

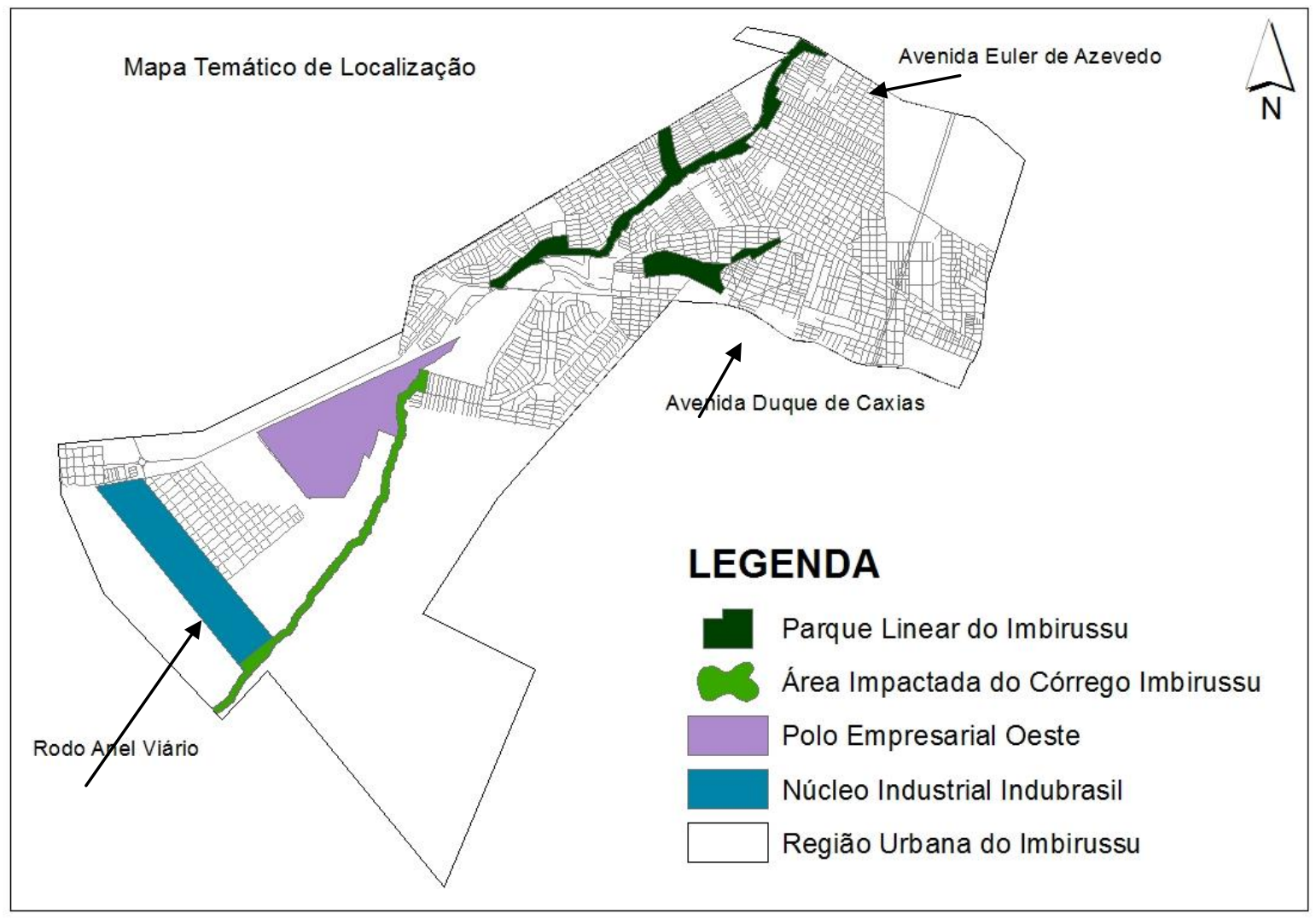

Figura 4 - Bacia ambiental do Imbirussu

Conforme Lima (2012) ao pesquisar a qualidade da água do córrego Imbirussu, constatou que nas regiões de amostragem em que não há cobertura de rede de esgoto, há aumento de coliformes termotolerantes, principalmente na região do Pólo Empresarial Oeste e do Núcleo Industrial Indubrasil onde está localizada a estação de tratamento de efluentes de um frigorífico e de um curtume e que tais valores elevados desta variável evidencia alguma falha na eficiência do tratamento dos efluentes destas atividades. 


\section{Then Fórum Ambiental \\ da Alta Paulista

Contudo, juntamente com o córrego Anhanduizinho, o córrego Imbirussu é um dos principais tributários e contribuintes para a poluição do rio Anhanduí (MS), apontado no Relatório (ANA, 2009) como um rio de alta disponibilidade hídrica, porém com baixa capacidade de assimilação de cargas de esgotos em consequência da elevada carga orgânica associada à densidade populacional e de atividades industriais (BOTELHO, 2009).

\section{CONCLUSÕES}

Conclui-se que em decorrência do crescimento populacional surge a necessidade de organizar os espaços de uma forma mais racional e que as mudanças constatadas na paisagem da bacia ambiental ocorreram a partir das mais diversas relações existentes entre sociedade e meio ambiente.

Essa dinâmica do espaço retrata a relevância da realização de estudos temporais sobre o uso e ocupação do solo como forma de interpretar e conduzir o desenvolvimento regional sustentável, contribuindo como um modelo de análise das transformações exercidas pelo homem sobre o meio no sentido de conduzir futuras ocupações e evitar consequências desastrosas.

A utilização de imagens de satélites orbitais trabalhadas em um Sistema de Informação Geográfico - SIG, gratuito e nacional, possibilitou a análise e interpretação das formas de uso e ocupação do solo, baseado também em documentos, fatos históricos e pesquisa de campo.

A pesquisa também demonstrou que problemas ambientais e má gestão do planejamento e ordenamento territorial estão associados a vontades políticas, contudo, podendo inclusive contribuir para a tomada de decisões ao detectar, apontar e apresentar detalhadamente o processo de uso e ocupação da Bacia Ambiental do Imbirussu a partir de uma análise integrada dos elementos que compõem a paisagem. 


\section{REFERÊNCIAS}

BOTELHO, R. G. M. Bacias hidrográficas urbanas. In: GUERRA, A. J. T.(org). Geomorfologia urbana. 1 ed. Rio de Janeiro: Bertrand Brasil, 2011. Capítulo: (p.71-110).

BRASIL. Lei Complementa n. 29, de 22 de fevereiro de 2005. Estabelece normas para o funcionamento do programa de incentivos para o desenvolvimento econômico e social de Campo Grande - MS, e dá outras providências. 2005. Disponível em: < http://www.pmcg.ms.gov.br/sedesc/canaisTexto?id_can=2183> Acesso em: 05 de nov. 2012.

CARVALHO, G. A. LAENDER, B. T. Georeferenciamento no SPRING. Universidade Federal de Minas Gerais. Instituto de Geociências. Departamento de Geografia. 2007. Disponível em:

http://www.arq.ufmg.br/SiteLabGeo/SigBasico/apostilas/ImportExport.pdf> Acesso em: 13 de nov. 2012.

EMBRAPA. Monitoramento por satélite. Como interpretar imagens do satélite Landsat. 2000. Disponível em:< http://www.cdbrasil.cnpm.embrapa.br/txt/inte.htm> Acesso em: 2 out. 2012.

FLORENZANO, T. G. Imagens de Satélite para estudos Ambientais. 3 ed. São Paulo: Oficina de Texto, 2011. $114 \mathrm{p} ; 115 \mathrm{p}$.

FREITAS, R.N. Aplicação de técnicas de geoprocessamento na avaliação dos vazios urbanos existentes na cidade de São José dos Campos, SP, em 2000. In: Anais XII Simpósio brasileiro de sensoriamento remoto, Goiânia, Brasil, INPE: 2005, p. 16-21.

IBGE - Instituto Brasileiro de Geografia e Estatística. Manual técnico de uso da terra. 2 ed. Rio de Janeiro: IBGE, 2006. 95 p. (Manuais Técnicos em Geociências, n. 7.).

LIMA, E. B. Diagnóstico e análise ambiental da microbacia do Imbirussu, Campo Grande - MS. 2012. Dissertação (Mestrado em Meio Ambiente e Desenvolvimento Regional) - Universidade Anhanguera - UNIDERP.

MARCONDES, M. J. A. Cidade e natureza: proteção dos mananciais e exclusão social. 1 ed. São Paulo: Studio Nobel: Editora da Universidade de São Paulo: FAPESP, 1999 - (Coleção cidade aberta)

PARANHOS FILHO, A.C; LASTORIA G.; TORRES T.G. Sensoriamento Ambiental Aplicado. Introdução as Geotecnologias. Ed. UFMS. Campo Grande -MS, 2008.

PLANURB. Perfil socioeconômico de Campo Grande - MS. 2012. Disponível em:< http://www.pmcg.ms.gov.br/sisgran > Acesso em 6 de dez. 2013. 
PLANURB. Relatório de Avaliação Ambiental (RAA). Programa de Desenvolvimento Integrado e Qualificação Urbana de Campo Grande/MS - Viva Campo Grande. 2007. Disponível em: <http://www.pmcg.ms.gov.br/planurb/downloads?categoria=36> Acesso em: 13 nov. 2012.

SANTOS, M. A Natureza do Espaço. Técnica e tempo, razão e emoção. 2 ed. São Paulo: HUCITEC. 1996.83 p; 242 p.

SANTOS, R. S. Planejamento Ambiental. Teoria e prática. 1 ed. São Paulo: Oficina de textos, 2004. 23 p; 43 p. 